\title{
Development and Validation of a UHPLC-MS/MS Method for the Analysis of Fusarium Mycotoxins in Onion
}

\author{
Sari Rämö ${ }^{1}$ (D) Minna Haapalainen ${ }^{2}$ (D) Satu Latvala ${ }^{3}$ (D) \\ Received: 27 October 2020 / Accepted: 9 February 2021 / Published online: 8 March 2021 \\ (C) The Author(s) 2021
}

\begin{abstract}
Fusarium basal rot (FBR) of onion is a serious disease problem worldwide. The Fusarium species causing FBR can also produce mycotoxins that are potentially harmful to humans and animals. In this study, a multiple reaction monitoring technique with ultrahigh-performance liquid chromatography-tandem mass spectrometry (MRM UHPLC-MS/MS) was developed and validated for onion matrix to study Fusarium mycotoxins in the harvested onions. This study was focused on fumonisins $\mathrm{B}_{1}, \mathrm{~B}_{2}$, and $\mathrm{B}_{3}\left(\mathrm{FB}_{1}\right.$, $\mathrm{FB}_{2}$, and $\mathrm{FB}_{3}$ ), beauvericin (BEA), and moniliformin (MON), which are the main mycotoxins produced by Fusarium oxysporum and Fusarium proliferatum. In the in-house validated protocol, the onion samples were extracted with methanol:water (3:1) using magnetic stirring for $15 \mathrm{~min}$. FBs and BEA were determined directly from the filtered extracts, whereas MON required sample concentration prior to analysis. No cleanup of extracts was needed prior to analysis. The target mycotoxins were separated on an Acquity UPLC system BEH C18 column with gradient elution. Mycotoxins were identified and quantified using ${ }^{13} \mathrm{C}-\mathrm{FB}_{1}$ as internal standard. Minor matrix effect was compensated using multi-point matrix-matched calibration curves with uninfected onion sample. For the mycotoxins studied, a good linearity was obtained $\left(R^{2} \geq 0.99\right)$ and the recoveries were in the range of $67-$ $122 \%$, with the highest standard deviation for MON, 22\%. The limits of quantification were from 2.5 to $10 \mathrm{ng} \mathrm{g}^{-1}$ in onion matrix. The method was successfully employed for the analysis of mycotoxins in harvested onions showing FBR symptoms and found to be infected with $F$. oxysporum and $F$. proliferatum.
\end{abstract}

Keywords Fusarium · Onion · Fumonisin · Moniliformin · Beauvericin · UHPLC-MS/MS

\section{Introduction}

Cultivated onion (Allium cepa) suffers from infections caused by various pathogens, mostly by fungi in the genera Fusarium and Botrytis. Fusarium basal rot (FBR) is a serious disease problem worldwide in onions, causing substantial losses during the growing season and in the storage. The rot starts from the roots and basal plate, and then spreads upwards inside the bulb and gradually spoils it (Galvan et al. 2008; Carrieri et al. 2013; Sasaki et al. 2015a). The pathogenic Fusarium

Sari Rämö

sari.ramo@luke.fi

1 Natural Resources, Natural Resources Institute Finland (Luke), Myllytie 1, FI-31600 Jokioinen, Finland

2 Department of Agricultural Sciences, University of Helsinki, Latokartanonkaari 7, FI-00014 Helsinki, Finland

3 Natural Resources, Natural Resources Institute Finland (Luke), Tietotie 4, FI-31600 Jokioinen, Finland oxysporum f. sp. cepae and Fusarium proliferatum are among the Fusarium sp. that have been reported to cause FBR in many countries where onion is grown (Bayraktar and Dolar 2011; Taylor et al. 2013; Sasaki et al. 2015a, b). Also in Finland, $F$. oxysporum and $F$. proliferatum are among the most common Fusarium species observed in onion sets and onion harvest, and the primary source of the pathogenic Fusarium strains is the use of imported onion sets (Haapalainen et al. 2016).

Infections with $F$. oxysporum and $F$. proliferatum not only spoil the onion quality but also cause a potential risk of onion contamination with mycotoxins, which are known to have many harmful effects on humans and animals (Desjardins and Proctor 2007; Lee and Ryu 2015; Fremy et al. 2019). Traditional Fusarium mycotoxins, like trichothecenes, fumonisins (FBs), and zearalenone (Hietaniemi et al. 2004, 2016; Shephard et al. 2007; Mahnine et al. 2012; Marin et al. 2013; Al-Taher et al. 2017), have been extensively studied in cereals and feed, and many risk assessment studies and legislation are available on them (EC 1881/ 2006; Shephard et al. 2007; Lee and Ryu 2015). In contrast, not much research 
has been done on Fusarium mycotoxins, both traditional and emerging mycotoxins like beauvericin (BEA), enniatins, and moniliformin (MON), in field vegetables. Until recently, risk assessment studies on vegetables have been lacking for several mycotoxins. Van de Perre et al. (2014) analyzed mycotoxins in tomatoes, bell peppers, onions, and soft red fruits, and found alternariol, alternariol monomethyl ether, ochratoxin $\mathrm{A}$, and fumonisins $\mathrm{B}_{1}, \mathrm{~B}_{2}$, and $\mathrm{B}_{3}\left(\mathrm{FB}_{1}, \mathrm{FB}_{2}, \mathrm{FB}_{3}\right)$. However, only Penicillium species were identified in the onion samples, showing no high levels of toxins, and the study was mostly focusing on the findings in the tomato products. Alternariol and alternariol monomethyl ether were also detected in strawberry by Dong et al. (2019), and tenuazonic acid in tomato juice, when seven mycotoxins were analyzed in fruits and vegetables during storage. The ability of Fusarium isolates originating from onion, garlic, and asparagus to produce mycotoxins has been studied in vitro by culturing the fungi on either maize or rice medium (Stankovic et al. 2007; Waskiewicz et al. 2010; Irzykowska et al. 2012). In these studies, the main mycotoxins produced by $F$. oxysporum $\mathrm{f}$. sp. cepae were shown to be MON and $\mathrm{FB}_{1}$ (Irzykowska et al. 2012), whereas $\mathrm{FB}_{1}$, BEA, MON, fusaric acid, and fusaproliferin were identified as the main mycotoxin species produced by F. proliferatum (Stankovic et al. 2007). To our knowledge, studies on production of these mycotoxins in the onion tissues infected by the Fusarium species have not been published before. However, we found one meeting abstract reporting that $\mathrm{FB}_{1}$ was detected in onions infected with F. proliferatum (Ellner and Grossmann 2010).

The chromatographic techniques earlier used for quantification of mycotoxins after sample extraction and cleanup were based on high-performance liquid chromatography (HPLC) with either diode array detector (DAD) without derivatization or fluorescence detector (FLD) after derivatization (Irzykowska et al. 2012). Trichothecenes have been usually quantified as their trimethylsilyl derivatives by gas chromatography-mass spectrometry (GC-MS) (Hietaniemi et al. 2004). Standard EU method for detection of FBs in cereal grain is based on extraction with acetonitrile:methanol:water (1:1:2), followed by immunoaffinity cleanup, derivatization by o-phthalaldehyde (OPA), and identification with HPLC-FLD (CEN 2004). FBs have also been detected in maize by lateral flow test (Molinelli et al. 2009) and 96-plate ELISA kits were used for monitoring FBs and aflatoxins in maize in Kenya (Kangethe et al. 2017). These results were confirmed by either liquid chromatographymass spectrometry (LC-MS/MS) or HPLC-FLD methods.

In recent years, LC-MS/MS methods have been widely applied to mycotoxin analysis (Kokkonen and Jestoi 2009; Mahnine et al. 2012; Van de Perre et al. 2014; Turner et al. 2015; Sadhasivam et al. 2017; Zhao et al. 2018; Dong et al. 2019; Jajić et al. 2019). Modern detection techniques, such as MS, enable detection of very low concentrations of mycotoxins and their structural identification simultaneously. In addition, MS allows the so-called multi-toxin methods to be applied for simultaneous detection of several mycotoxins, which saves time and money as well as enables a better assessment of the cooccurrence of mycotoxins (Jestoi 2008). This is a clear improvement compared to the HPLC techniques where every single step in the sample pretreatment can cause loss of recovery, the derivatization is time-consuming, and the reagents used are often harmful to both health and environment.

Even though LC-MS technique and other methods have been widely applied to study Fusarium mycotoxins like FBs, MON, and BEA in cereals (Jestoi 2008; Kokkonen and Jestoi 2009; Mahnine et al. 2012; Sadhasivam et al. 2017; Jajić et al. 2019), only few methods have been published for the analysis of Fusarium mycotoxins in vegetables or spices (Monbaliu et al. 2009; Yogendrarajah et al. 2013; Van de Perre et al. 2014; Zhao et al. 2018; Dong et al. 2019). Monbaliu et al. (2009) determined mycotoxins in sweet pepper after several cleanup procedures by LC-MS/MS method. Yogendrarajah et al. (2013) used so-called QuEChERS (quick, easy, cheap, effective, rugged, and safe) extraction for spices, without a cleanup procedure, followed by LCMS/MS detection. Van de Perre et al. (2014) reported of a method based on liquid chromatography/time-of-flight mass spectrometry (LC/TOF-MS) for the screening of mycotoxins in tomato, pepper, and onion. This method included only a simple extraction procedure without a cleanup. Zhao et al. (2018) used UHPLC-MS/MS method including cleanup procedures to study Fusarium mycotoxins in pepper, potato, tomato, and cucumber. However, these mass spectrometry methods have not been used for detection and quantification of mycotoxins in onions. Therefore, to be able to detect and analyze possible toxic contaminants in onions, the suitability of the sensitive UHPLC-MS/MS techniques for this purpose is needed to be examined.

The aims of this study were (i) to develop and validate a multiple reaction monitoring technique with ultra-highperformance liquid chromatography-tandem mass spectrometry method (MRM UHPLC-MS/MS) for onion matrix and (ii) to use the validated method to analyze mycotoxins produced by $F$. oxysporum and $F$. proliferatum in harvested onions.

\section{Materials and Methods}

\section{Chemicals and Reagents}

LC-MS grade methanol and acetonitrile were purchased from VWR (Prolabo, Leuven, Belgium). LC-MS grade formic acid was purchased from Thermo Fischer Scientific (Waltham, MA, USA). LC-MS grade water was prepared with Millipore system (Millipore, Billerica, MA, USA). 


\section{Stock and Standard Solutions}

Standard stock solutions of $\mathrm{FB}_{1}, \mathrm{FB}_{2}$, and $\mathrm{FB}_{3}$, each $50 \mu \mathrm{g}$ $\mathrm{mL}^{-1}$ in acetonitrile:water (1:1), MON $100 \mu \mathrm{g} \mathrm{mL}^{-1}$ in acetonitrile:water (9:1), BEA $100 \mu \mathrm{g} \mathrm{mL}^{-1}$ after dissolving into $1 \mathrm{~mL}$ of acetonitrile, and internal standard ${ }^{13} \mathrm{C}-\mathrm{FB}_{1}$ (ISTD) $25 \mu \mathrm{g} \mathrm{mL}^{-1}$ in acetonitrile:water (1:1) were all purchased from BioPure (Romer Labs, Tulln, Austria).

Working solution of ISTD (1000 $\left.\mathrm{ng} \mathrm{mL}^{-1}\right)$ was prepared in acetonitrile:water (1:1). Standard working solutions of the other mycotoxins were prepared at $5000 \mathrm{ng} \mathrm{mL}^{-1}$ concentration using the same solvents as used in the stock solutions. For calibration, three different mycotoxin mixtures were prepared from the standard working solutions using methanol as solvent. MycoMix 1 ( $500 \mathrm{ng} \mathrm{mL}^{-1}$ ) was prepared by combining $1 \mathrm{~mL}$ of each working solution (not ISTD) in a $10-\mathrm{mL}$ volumetric flask and filling it up with the solvent. MycoMix 2 (50 $\mathrm{ng} \mathrm{mL}^{-1}$ ) and MycoMix $3\left(5 \mathrm{ng} \mathrm{mL}^{-1}\right.$ ) were prepared from MycoMix 1 by serial 10-fold dilutions. All the standard solutions were stored at $4{ }^{\circ} \mathrm{C}$ and the MycoMix solutions were renewed annually.

\section{Onion Samples}

Onions (Allium cepa L.) showing FBR symptoms inside the bulb were found in 2017 in a survey on farms in South Savo and in South Karelia regions in eastern Finland, and in 2018 in the field trials conducted at Luke Piikkiö, in Southwest Finland. In both years, the onion samples were collected at harvest time, in August and September. Twenty of the onion bulbs cut in half with a knife and found having FBR symptoms - gray discoloration and softening of tissues at the basal end - were selected for test material for this study. The symptomatic and symptomless tissues of the onion were separated and then treated as individual samples. These tissue samples were cut up very finely and 1-g subsamples were transferred into $50-\mathrm{mL}$ polypropylene (PP) tubes. Three or four biological replicates per sample were prepared, depending on the availability of the onion tissue material. Samples were stored at $-20{ }^{\circ} \mathrm{C}$.

\section{Detection of Fusarium Fungi in the Samples}

DNA was extracted from 0.1 -g subsamples of the symptomatic and symptomless tissues of each onion sample using DNeasy Plant Mini kit (Qiagen, Hilden, Germany) according to the manufacturer's protocol. The presence of $F$. oxysporum and $F$. proliferatum in the samples was tested by end-point PCR using species-specific primer pairs CLOX1-F/CLOX2-R and TH5-F/TH6-R, as previously described (Haapalainen et al. 2016). Quantification of $F$. oxysporum DNA in the onion tissue DNA samples was performed by real-time PCR as described in Wang et al. (2019). Quantification of
F. proliferatum DNA in onion tissue DNA samples was performed by real-time PCR using new primers FprIGS-F7w (5'GTGCAGACCAGAGYGAACGTGGT-3') and FprIGS-R7 (5'-CCCATCAGCCAGAGAACCGACATC-3'), designed to bind to the ITS2 region between the $28 \mathrm{~S}$ and $5.8 \mathrm{~S}$ ribosomal RNA genes of $F$. proliferatum and yield a 90 -bp product. For reference, the onion DNA was quantified using the onionspecific primers AcCOX1F and AcCOX1R as previously described (Wang et al. 2019). Each $20-\mu \mathrm{L}$ reaction contained 10 $\mu \mathrm{L}$ of SYBR Green I Master Mix (Roche, Basel, Switzerland), forward and reverse primers at 300-nM concentration and $5 \mu \mathrm{L}$ of diluted DNA sample. PCR program with initial denaturation at $95^{\circ} \mathrm{C}$ for $5 \mathrm{~min}$ and 45 cycles of $95^{\circ} \mathrm{C}$ for $10 \mathrm{~s}, 60^{\circ} \mathrm{C}$ for $10 \mathrm{~s}$, and $72^{\circ} \mathrm{C}$ for $10 \mathrm{~s}$, followed by melting curve analysis, was run on LightCycler 480 real-time PCR instrument (Roche). Dilution series prepared of control samples containing measured concentrations of healthy onion DNA, $F$. oxysporum DNA, and $F$. proliferatum DNA were similarly run on real-time PCR, to determine the relation of cycle threshold $(\mathrm{Ct})$ value and the template DNA concentration. The sample DNA concentrations were then calculated using these standard curves.

\section{Sample Preparation}

One milliliter of methanol and $50 \mu \mathrm{L}$ of ISTD working solution were added on each $1-\mathrm{g}$ onion sample. The samples were then extracted with $5 \mathrm{~mL}$ of methanol:water (3:1) mixture for 15 min using magnetic stirring. The sample matrix was allowed to settle and the extract was then transferred into a test tube by pipetting. Extraction was repeated with $5 \mathrm{~mL}$ of methanol:water (3:1). Centrifugation between the extractions was required for few symptomatic onion samples. The extracts were combined and $1 \mathrm{~mL}$ of the combined extract was filtered through 0.2- $\mu \mathrm{m}$ GHP Acrodisc 13 Teflon filter (Pall Corporation, Ann Arbor, MI, USA) prior to UHPLC-MS/MS analysis. For MON analysis, $4 \mathrm{~mL}$ of combined extracts was concentrated by evaporating to dryness with nitrogen. The residue was dissolved in $1 \mathrm{~mL}$ of $0.1 \%$ formic acid in water (UHPLC gradient solvent A) and $0.1 \%$ formic acid in acetonitrile (UHPLC gradient solvent B) (1:1) and filtered for analysis. The samples were stored in dark at $4{ }^{\circ} \mathrm{C}$ before analysis.

\section{UHPLC-MS/MS Analysis}

Waters Acquity UPLC system equipped with Xevo TQ MS triple-quadrupole mass spectrometer (Milford, MA, USA) was used for separation and identification of mycotoxins. Mycotoxins were separated by gradient run on Acquity BEH C18-UPLC reversed phase column $(2.1 \times 100 \mathrm{~mm}$, I.D. 1.7 $\mu \mathrm{m})$ equipped with a VanQuard pre-column $(2.1 \times 5 \mathrm{~mm}$, I.D. $1.7 \mu \mathrm{m}$ ) with the same sorbent material (Waters, Milford, MA, USA). The gradient solvent system was composed of $0.1 \%$ 
formic acid in water (A) and $0.1 \%$ formic acid in acetonitrile (B), and the column temperature was $40{ }^{\circ} \mathrm{C}$ and flow rate $0.4 \mathrm{~mL} \mathrm{~min}^{-1}$, according to Waters Application note (Stead et al. 2014).

For UHPLC gradient runs, some minor modifications were made and two separate runs performed, a 15-min run with 2- $\mu \mathrm{L}$ injection volume was used for separation of FBs and BEA in the filtered sample extracts and a $7-\mathrm{min}$ run with $0.5-\mu \mathrm{L}$ injection volume was used for separation of MON in the concentrated sample extracts. The 15-min run was started with $100 \%$ solvent A, maintained for $2.5 \mathrm{~min}$. From 2.5 to $10 \mathrm{~min}$, solvent B was linearly increased from 0 to $75 \%$ and then increased in $0.1 \mathrm{~min}$ to $85 \%$ and maintained for $1.9 \mathrm{~min}$. Then, B was increased to $100 \%$ in $0.1 \mathrm{~min}$, maintained in $0.9 \mathrm{~min}$, and finally $\mathrm{B}$ was decreased to $0 \%$ in $0.1 \mathrm{~min}$ and maintained for $1.9 \mathrm{~min}$ to re-equilibrate the column prior to the next injection. The 7-min run was started with $100 \%$ A, maintained for $2.5 \mathrm{~min}$. From 2.5 to $4.5 \mathrm{~min}$, B was linearly increased from 0 to $75 \%$ and then increased in $0.6 \mathrm{~min}$ to $100 \%$ and maintained for $0.9 \mathrm{~min}$. Finally, B was decreased to $0 \%$ in $0.1 \mathrm{~min}$, and maintained for $0.9 \mathrm{~min}$ to reequilibrate the column prior to the next injection.

Xevo TQ MS triple-quadrupole mass spectrometer was equipped with an electrospray ionization source (ESI) operating in a positive mode $\left(\mathrm{ESI}^{+}\right)$for $\mathrm{FBs}$ and BEA, and in a negative mode (ESГ) for MON. The MS capillary voltage was $1.5 \mathrm{kV}$ for FBs and BEA, and $0.5 \mathrm{kV}$ for MON. The ion source temperature was $150{ }^{\circ} \mathrm{C}$ and the desolvation temperature was $600^{\circ} \mathrm{C}$ for $\mathrm{FBs}$ and BEA, and $500{ }^{\circ} \mathrm{C}$ for MON. The cone and desolvation gas flows (both nitrogen) were $30 \mathrm{~L} \mathrm{~h}^{-1}$ and $900 \mathrm{~L} \mathrm{~h}^{-1}$ for FBs and BEA and $30 \mathrm{~L} \mathrm{~h}^{-1}$ and $1000 \mathrm{~L} \mathrm{~h}^{-1}$ for MON. Argon was used as collision gas with flow $0.24 \mathrm{~mL} \mathrm{~min}{ }^{-1}$. The specific MS/MS parameters for each mycotoxin are presented in Table 1. Data was acquired using the multiple reaction monitoring (MRM) mode. Data acquisition and processing were carried out using MassLynx V4.1 software.

\section{Calibration}

Mycotoxins were quantified with internal standard method using ${ }^{13} \mathrm{C}-\mathrm{FB}_{1}$ (ISTD). Calibrations were made both in the extraction solvent mixture and the onion matrix to estimate possible matrix effect. Eleven calibration levels, 0, 0.5, 1, 2.5, $5,10,25,50,100,250$, and $500 \mathrm{ng} \mathrm{g}^{-1}$, were used and prepared by adding MycoMix dilution (1, 2, or 3) and methanol in total volume of $1 \mathrm{~mL}$. ISTD working solution $(50 \mu \mathrm{L})$ was added in each calibration sample. Only $1 \mathrm{~mL}$ of methanol and ISTD was added in standard $0 \mathrm{ng} \mathrm{g}^{-1}$. For matrix-matched calibration, $1 \mathrm{~g}$ of onion matrix per sample was used. The onion tissue was verified uninfected by Fusarium-specific PCR as described in Haapalainen et al. (2016) and free of those mycotoxins studied in this work. Prior to analysis, the calibration samples were extracted and treated as described for onion samples in "Sample Preparation." Calculations were made using the response value obtained from TargetLynx ([Standard area/ISTD area] * [concentration of ISTD]) on $Y$ axis and the actual concentration of the standards on $X$ axis to obtain a standard curve for each mycotoxin. Matrix effect was evaluated by comparing the slope of calibration curves in pure solvent mixture and matrix-matched extracts.

Table 1 MS/MS parameters of Fusarium mycotoxins. Multiple reaction monitoring settings (MRMs) marked in bold were used for identification and quantification and the other MRMs for confirmation

\begin{tabular}{|c|c|c|c|c|c|c|c|}
\hline Mycotoxin & $\begin{array}{l}\text { Retention } \\
\text { time (min) }\end{array}$ & Ionization mode & Molecular weight & $\begin{array}{l}\text { Parent } \\
\text { ion }(\mathrm{m} / \mathrm{z})\end{array}$ & $\begin{array}{l}\text { Daughter } \\
\text { ion }(\mathrm{m} / z)\end{array}$ & $\begin{array}{l}\text { Cone } \\
\text { voltage (V) }\end{array}$ & $\begin{array}{l}\text { Collision } \\
\text { energy }(\mathrm{eV})\end{array}$ \\
\hline Moniliformin & $0.8 \mathrm{a} \pm 0.1$ & ESI $^{-}$ & 98 & 96.9 & 40.9 & 27 & 10 \\
\hline \multirow[t]{2}{*}{ 13C-Fumonisin $\mathrm{B}_{1}$ (ISTD) } & \multirow[t]{2}{*}{$4.5 \mathrm{a} / 7.0 \mathrm{~b} \pm 0.1$} & \multirow[t]{2}{*}{$\mathrm{ESI}^{+}$} & \multirow[t]{2}{*}{755.83} & \multirow[t]{2}{*}{756.5} & 356.3 & 50 & 40 \\
\hline & & & & & 374.4 & 50 & 40 \\
\hline \multirow[t]{2}{*}{ Fumonisin $\mathrm{B}_{1}$} & \multirow[t]{2}{*}{$7.0 \mathrm{~b} \pm 0.1$} & \multirow[t]{2}{*}{$\mathrm{ESI}^{+}$} & \multirow[t]{2}{*}{721.83} & \multirow[t]{2}{*}{722.1} & 334.3 & 50 & 40 \\
\hline & & & & & 352.3 & 50 & 40 \\
\hline \multirow[t]{2}{*}{ Fumonisin $\mathrm{B}_{2}$} & \multirow[t]{2}{*}{$7.7 b \pm 0.1$} & \multirow[t]{2}{*}{$\mathrm{ESI}^{+}$} & \multirow[t]{2}{*}{705.83} & \multirow[t]{2}{*}{706.3} & 336.3 & 50 & 40 \\
\hline & & & & & 318.3 & 50 & 40 \\
\hline \multirow[t]{2}{*}{ Fumonisin $\mathrm{B}_{3}$} & \multirow[t]{2}{*}{$7.4 b \pm 0.1$} & \multirow[t]{2}{*}{$\mathrm{ESI}^{+}$} & \multirow[t]{2}{*}{705.83} & \multirow[t]{2}{*}{706.3} & 336.3 & 50 & 40 \\
\hline & & & & & 318.3 & 50 & 40 \\
\hline \multirow[t]{4}{*}{ Beauvericin } & \multirow[t]{4}{*}{$11.4 \mathrm{~b} \pm 0.1$} & \multirow[t]{4}{*}{$\mathrm{ESI}^{+}$} & \multirow[t]{4}{*}{783.96} & \multirow[t]{4}{*}{784.6} & 262.2 & 34 & 28 \\
\hline & & & & & 244.2 & 34 & 28 \\
\hline & & & & & 134.1 & 34 & 66 \\
\hline & & & & & 234.2 & 34 & 38 \\
\hline
\end{tabular}

\footnotetext{
${ }^{a}$ Retention time for 7 min UHPLC gradient run
}

${ }^{\mathrm{b}}$ Retention time for 15 min UHPLC gradient run 


\section{Quality Control During Daily UHPLC-MS/MS Run}

The UHPLC-MS/MS run was started with no injection to monitor interfering signals from the background (room air or UHPLC gradient). Then, pure extraction solvent, or UHPLC gradient in the case of MON, was injected to monitor possible background interference signals from solvents, syringe filters, or sample bottles. In addition, background (blank) samples, with or without ISTD, prepared as samples without onion matrix, were run before calibration samples to monitor if there were any interference signals from the different steps of the protocol. Calibration samples were run from 0 to $500 \mathrm{ng} \mathrm{g}^{-1}$, followed by two solvent injections before and after the sample injections, to prevent any carry over from the most concentrated calibration sample. As a control sample, the $50 \mathrm{ng} \mathrm{g}^{-1}$ standard, followed by a solvent injection, was run after every 9-12 samples.

\section{Method Validation}

The method was validated in-house, according to Kemian metrologian opas J6/2005 (MIKES 2005). The following analytical parameters were evaluated during the validation process on onion matrix: (i) selectivity and specificity; (ii) linearity, repeatability, reproducibility, and matrix effect; and (iii) sensitivity as limit of detection (LOD) and limit of quantification (LOQ), quantitative range, and recovery. Matrix effect was studied during both development and validation of the method.

\section{Results and Discussion}

\section{Optimization of the Sample Preparation Procedure}

For multi-toxin analysis, the sample preparation and finding an extraction solvent suitable for all the studied mycotoxins are of major importance, because the extraction step and the choice of extraction solvent affect the recovery of the different compounds. In this study, four different extraction solvent mixtures were evaluated for their suitability for onion: A, methanol:water $(3: 1)$, used for extraction of FBs by Waskiewicz et al. (2010); B, acetonitrile:methanol:water (16:3:1), used for extraction of BEA and MON by Waskiewicz et al. (2010); C, acetonitrile:water (84:16), which is a universal extraction solution for mycotoxins and also the extraction solution used in the accredited trichothecene method of Natural Research Institute Finland (Luke) (Hietaniemi et al. 2004); and D, acetonitrile:methanol:water (1:1:2), used for extraction of FBs from cereals according to the method of European Committee for Standardization (CEN 2004).

Sample matrix can either suppress or enhance the MS signal of any compound in the extraction solvent in LC-MS technique (Kokkonen and Jestoi 2009; Malysheva et al. 2013; Serrano et al. 2013; Zhao et al. 2018). Therefore, each extraction solvent mixture with and without the PCR-verified uninfected onion matrix was spiked with $100 \mathrm{ng}$ of each mycotoxin prior to extractions, and the possible onion matrix effect was studied. The extractions with the four different solvent mixtures were repeated three times. Two different extraction techniques were also compared: mixing by Vortex blender for $3 \mathrm{~min}$ and magnetic stirring for $15 \mathrm{~min}$. These techniques performed equally well for both the spiked extraction solvent mixtures and the spiked healthy onion. However, magnetic stirring was found to be more effective in extracting BEA from onions with $F$. oxysporum infection (data not shown), and thus this method was used in all the extractions. Most of the FBs and BEA were dissolved in the first and the second extractions. The combined peak areas of the ions from these two extractions are presented in Table 2. On onion background, the peak areas of FBs were similar with all the four extraction solvents. However, on pure solvent background, the peak areas of FBs were suppressed with the extraction solvents B and C. In earlier studies, we had noticed the similar phenomenon with 9-fluorenylmethylchloroformate derivative of glyphosate in pure Milli-Q water in comparison to surface or drain waters from the test fields (Rämö, unpublished results). For FBs, a minor enhancing matrix effect was detected with the solvent mixtures A and D. All the extraction solvent mixtures were found equally effective for extracting BEA; however, a suppressing matrix effect was found on onion matrix with all the other solvent mixtures except A. The solvent $\mathrm{D}$ was excluded, due to the difficulties in filtering the

Table 2 Comparison of quantitative peak areas of fumonisins and beauvericin from extractions with different solvent mixtures, either pure solvent mixture or onion matrix-matched extracts, both spiked with $100 \mathrm{ng}$ of each mycotoxin. Extractions were done by magnetic stirring for $15 \mathrm{~min}$. Values in the table are sum of peak areas from the 1 st and $2 \mathrm{nd}$ extractions. Extraction solvents were A, methanol:water (3:1); B, acetonitrile:methanol:water (16:3:1); C, acetonitrile:water (84:16); and $\mathrm{D}$, acetonitrile:methanol:water $(1: 1: 2)$

\begin{tabular}{lllll}
\hline Mycotoxin & \multicolumn{4}{l}{ Peak area in extraction solvent mixture } \\
\cline { 2 - 5 } & $\mathrm{A}$ & $\mathrm{B}$ & $\mathrm{C}$ & $\mathrm{D}$ \\
\hline${ }^{13}$ C-Fumonisin $\mathrm{B}_{1}$ in solvent & 3828 & nd & 891 & 4156 \\
${ }^{13}$ C-Fumonisin $\mathrm{B}_{1}$ in onion & 4096 & 3572 & 4616 & 4233 \\
Fumonisin $\mathrm{B}_{1}$ in solvent & 3852 & nd & 925 & 3914 \\
Fumonisin $\mathrm{B}_{1}$ in onion & 4148 & 3292 & 4172 & 4200 \\
Fumonisin $\mathrm{B}_{2}$ in solvent & 7714 & nd & 2567 & 7620 \\
Fumonisin $\mathrm{B}_{2}$ in onion & 8132 & 7086 & 8813 & 8591 \\
Fumonisin $\mathrm{B}_{3}$ in solvent & 6982 & nd & 2377 & 7189 \\
Fumonisin $\mathrm{B}_{3}$ in onion & 6943 & 6429 & 6825 & 7808 \\
Beauvericin in solvent & 41,585 & 43,566 & 42,830 & 37,799 \\
Beauvericin in onion & 41,523 & 37,945 & 31,600 & 30,177 \\
\hline
\end{tabular}


onion sample extracts. The extraction with solvent mixture A (methanol:water 3:1) with magnetic stirring for 15 min was chosen for further method development and validation. The recovery for FBs and BEA was $\geq 96 \%$ after two repeated extractions, and the matrix effect was found minor with both FBs and BEA (Table 2). The chosen extraction method was also applicable, even though not optimal, for MON when the extract was concentrated prior to analysis. Sewram et al. (1999) used $95 \%$ acetonitrile in water for extracting MON from maize. Parich et al. (2003) found that $84 \%$ acetonitrile in water was the best for extraction of MON from maize, after testing several acetonitrile:water ratios. Jestoi et al. (2003) used the same solvent for extracting MON from Finnish grain samples. However, solvent C ( $84 \%$ acetonitrile) was not suitable for the multi-toxin method developed in this study, because the peak areas for FBs in the pure solvent were small in the UHPLCMS/MS detection.

Onion matrix does not contain pigments that would disturb the toxin analysis. Therefore, no cleanup procedure of the onion extract was needed to be included into the protocol. The protocol for onion extract reported by Van de Perre et al. (2014) did not include a cleanup procedure either. Instead, for extracts of vegetables containing plenty of pigments, like sweet pepper and tomato, cleanup procedures are needed prior to analysis (Monbaliu et al. 2009; Zhao et al. 2018). Zhao et al. (2018) reported that the crude extracts from vegetables containing plenty of pigments and matrix interferences resulted in matrix effect and affected method reproducibility. To remove matrix interferences in the crude extract of vegetables, Zhao et al. (2018) employed dispersive solid-phase extraction (dSPE) method for sample purification.

\section{Optimization of UHPLC-MS/MS Conditions}

Mycotoxins were identified according to the multiple reaction monitoring settings (MRMs) and retention times (RTs). The MS/MS conditions used with the studied mycotoxins are listed in Table 1. Usually, two MRMs are required for quantitative detection (SANTE/12089/2016), but MON has only one suitable MRM (Kokkonen and Jestoi 2009). MRMs reported by Stead et al. (2014) were used for $\mathrm{FB}_{1}$ and $\mathrm{FB}_{2}$. $\mathrm{FB}_{2}$ and $\mathrm{FB}_{3}$ have the same MRMs, but different RTs (7.7 and 7.4 min, respectively) in the chosen UHPLC gradient settings. For ${ }^{13} \mathrm{C}_{-} \mathrm{FB}_{1}$, one MRM was found from literature (Al-Taher et al. 2017) and another one with daughter scan function of the instrument with $1000 \mathrm{ng} \mathrm{mL}^{-1}$ concentration. IntelliStart of the instrument was used for finding daughter ions for BEA with $1000 \mathrm{ng} \mathrm{mL}^{-1}$ concentration. Daughter scan function was also used to confirm the daughter ion for MON with $5000 \mathrm{ng} \mathrm{mL} L^{-1}$ concentration. All MRMs used in this study were confirmed by daughter scan function of the instrument, and the values can therefore differ from the ones presented in the original publications. The most abundant daughter ion was used for quantification of FBs and the secondary daughter ion for confirmation. However, the daughter ion with the highest $\mathrm{m} / \mathrm{z}$ value, 262.2, was used for quantification of BEA, although it was only the third abundant daughter ion. It had the best peak shape and there was less interference with lower concentration in onion matrix compared to $\mathrm{m} / \mathrm{z}$ values 134.1 or 244.2, which were used in Waters Application note (Stead et al. 2014) for quantification and confirmation. The third confirmation ion, 234.2, was also found with the lowest detectable concentration. All four daughter ions of BEA were followed in onion extracts because of the interfering background signals which were detected during the research.

Two ionization energies were compared for FBs and BEA in a positive mode $\left(\mathrm{ESI}^{+}\right): 1.5 \mathrm{kV}$, used in the final protocol, gave higher peak areas than $3.5 \mathrm{kV}$, which was used in Waters Application note (Stead et al. 2014). For MON, ionization energy $0.5 \mathrm{kV}$ was better than $2.5 \mathrm{kV}$ in a negative mode (ESI-) (data not shown).

The development of UHPLC method was started with the UHPLC gradient used in Waters Application note (Stead et al. 2014). The gradient solvent system was composed of $0.1 \%$ formic acid in water (A) and $0.1 \%$ formic acid in acetonitrile (B). However, the gradient run was started with solvent A (100\%), because of the highly polar MON, for which RT was $0.8 \mathrm{~min}$. Separation of MON peak from the onion matrix peak was better achieved in concentrated extract dissolved in UHPLC gradient solvents A and B (1:1) than in filtered sample extract. Also, minor modifications were done in the proportions of solvent $\mathrm{B}$ in the gradient compared to the original 15-min gradient: the proportion of solvent $B$ was raised from 0 to $75 \%$ instead of the original $70 \%$, to achieve a better peak shape for $\mathrm{FB}_{2}$. In addition, the proportion of solvent $\mathrm{B}$ was only raised to $85 \%$ instead of the original $90 \%$, to achieve better separation of BEA peak from the interfering signal from the background (data not shown).

Finally, two separate UHPLC gradient programs as described in "UHPLC-MS/MS Analysis" above were used: a 15-min run was used for filtered sample extracts for analysis of FBs and BEA and a 7-min run was used for concentrated sample extracts for analysis of MON. The best separation and most usable peak areas were achieved when the sample injection volume was $2 \mu \mathrm{L}$ for FBs and BEA and $0.5 \mu \mathrm{L}$ for MON. Injection volumes of $4 \mu \mathrm{L}$ and $6 \mu \mathrm{L}$ were also tested for filtered sample extracts. Although the peak areas were then higher for FBs and BEA, the peak shapes were better with $2-\mu \mathrm{L}$ injection. With $2-\mu \mathrm{L}$ injection, it was also possible to run samples longer before the necessary cleaning procedure of the sample cone of ion source. The same amount of onion matrix was injected into the instrument with the $0.5-\mu \mathrm{L}$ injection of concentrated extract and with the $2-\mu \mathrm{L}$ injection of filtered extract. Peak areas of MON in the concentrated sample extract were lower than peak areas of FBs and BEA in filtered extract with the same concentration. Higher 
injection volumes were tested for MON, but peak areas were even lower or not detected at all when volumes of $2 \mu \mathrm{L}$ or higher were used.

\section{Optimization of Calibration}

Ideally, isotopically labeled standards are used as ISTD for each studied mycotoxin to achieve accurate mycotoxin quantification by LC-MS/MS (Rubert et al. 2012). However, no ${ }^{13} \mathrm{C}$-labeled isotopes are commercially available for MON and BEA, whereas for $\mathrm{FB}_{1}, \mathrm{FB}_{2}$, and $\mathrm{FB}_{3}$ they are available. In this work, ${ }^{13} \mathrm{C}-\mathrm{FB}_{1}$ was used as the standard, because $\mathrm{FB}_{1}$ had been found the most toxic and the most common FB in maize matrix (Shephard et al. 2007). Matrix-matched calibration has been used when suitable ISTD are not commercially available or they are too expensive (Rubert et al. 2011, 2012; Serrano et al. 2013). In this study, ${ }^{13} \mathrm{C}-\mathrm{FB}_{1}$ was used as the ISTD for all mycotoxins, and matrix-matched calibration was used to compensate any possible matrix effect. TargetLynx of the instrument directly calculated the concentrations of mycotoxins in the samples, when ISTD and calibration standards were added in the sample matrix that was free of the studied compounds before extraction, and both the calibration samples and the research samples were prepared similarly.

Two different concentrations, $50 \mathrm{ng}$ and $100 \mathrm{ng}$ of ISTD, were tested with uninfected and Fusarium-infected onion samples. For quantification of FBs and BEA in filtered sample extracts and MON in concentrated extracts, $50 \mathrm{ng}$ of ISTD was found adequate (data not shown). The lower amount of ISTD used in the protocol is also an economical option for the routine analysis.

The MycoMix solutions for a calibration range of 0 $500 \mathrm{ng} \mathrm{g}^{-1}$ were prepared in methanol. A broad calibration range was selected because there was no previous data about the concentrations of the studied mycotoxins in field-grown onions in Finland. Acetonitrile was first used to prepare the solutions, but the calibration curves for FBs were not linear. When calibration was repeated with the solutions made in methanol, the curves were linear also for FBs. Uninfected onion tissue, tested free of the mycotoxins studied in this work, was used for multi-point matrix-matched calibration, which was compared to the calibration made in pure solvent. Calibration curves, which were used for quantification of the studied mycotoxins in onion, were made both with filtered calibration sample extracts and with concentrated calibration sample extracts dissolved in UHPLC gradient (1:1). The calibration levels with recovery $80-120 \%$ of concentrations were included in the calibration curves. The slopes for calibration curves, both in solvent and in onion matrix, intercepts of $Y$ axis, and correlations $R^{2}$ are presented in Table 3. Ideally, all

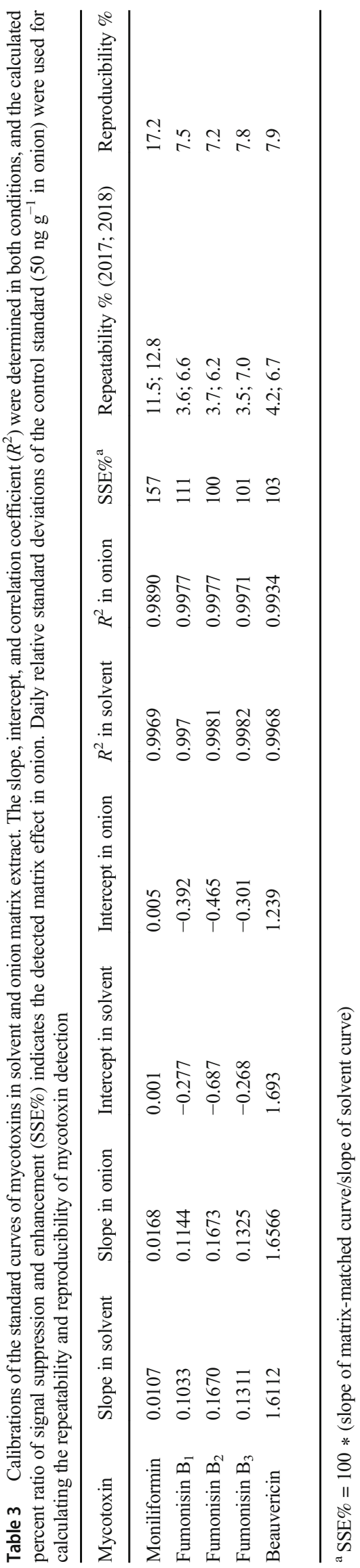


the mycotoxins of interest could be quantified in the filtered sample extracts without concentrating them. In this study, however, separation of MON from the onion matrix was unfortunately too poor, and thus concentrating the extract and exchanging the solvent were required prior to quantification. In addition, lower concentrations of MON could be detected with the concentrated calibration standards, which supports the choice of this method for MON. For quantification of FBs, both calibration curves were eligible, whereas for BEA satisfactory linearity was not always achieved with the concentrated calibration samples. Therefore, calibration samples in filtered sample extract were used for both the FBs and BEA.

\section{Method Validation}

\section{Selectivity and Specificity}

The selectivity of the method developed was studied and monitored at the beginning of the method validation and also during daily UHPLC-MS/MS run. The laboratory glassware, extraction solvent, and other reagents and the uninfected onion tissue sample were tested for the studied mycotoxins. Blank samples (= no onion matrix) and uninfected onion samples were analyzed with and without ISTD. Background signals of FBs, including ${ }^{13} \mathrm{C}-\mathrm{FB}_{1}$, and $\mathrm{MON}$ were not detected, but a minor background signal of BEA was detected. Since the background peak of BEA was lower in the uninfected onion tissue than in the reagent blank, the source of this interfering signal was probably either the reagents or glassware or an air contamination. Signals of FBs or MON were not detected in the uninfected onion tissue.

The specificity of the method is composed of the characteristic MRM values and the separate retention times (RT) for each mycotoxin. The identification of mycotoxins was confirmed based on the correct RT, mass of the parent ion, mass of the daughter ions, and ratios of those daughter ions that were used as the quantification and confirmation ions (Tables 1 and 4).
Linearity, Repeatability, Reproducibility, and Matrix Effect

Both solvent and matrix-matched calibrations, prepared as described in "Calibration," were used to evaluate linearity of the slope of calibration curves for all the tested mycotoxins over the selected concentration range, although only minor matrix effect was detected in onion for FBs and BEA during method development. Correlation coefficient $\left(R^{2}\right)$ was used to assess the linearity. The correlation coefficients for the studied mycotoxins were between 0.9890 and 0.9982 , indicating a good linear relationship between the quantitative peak areas and mycotoxin concentrations (Table 3). The intercepts of BEA showed minor interference from the background. Several matrix-matched calibrations were prepared during the study, all with linear curves and similar slopes, indicating good repeatability and reproducibility. Daily relative standard deviations of the control standard (50 $\mathrm{ng} \mathrm{g}^{-1}$ in onion) were used for calculating repeatability (\%) and reproducibility (\%) for the method (Table 3). Matrix effect was further studied by comparing the slopes of matrix-matched calibration curves to solvent curves and calculated as the ratio of signal suppression and enhancement: SSE\% $=100 *$ (slope of matrix-matched curve/slope of solvent curve). For $\mathrm{FB}_{2}, \mathrm{FB}_{3}$, or BEA, only a minor effect or no matrix effect was observed (Table 3). For $\mathrm{FB}_{1}$, SSE\% was 111 , although ${ }^{13} \mathrm{C}-\mathrm{FB}_{1}$ was used as ISTD and thus the matrix effect was assumed to be minor. The highest, enhancing matrix effect in onion was detected for MON (Table 3), which was studied in concentrated extract dissolved in UHPLC gradient (1:1). This was different from Kokkonen and Jestoi (2009), who detected a noticeable suppressing matrix effect for MON in grain.

\section{Sensitivity}

The limit of detection (LOD) and the limit of quantification (LOQ) were used to estimate method performance in terms of sensitivity. The correct retention time, a sufficient signal to noise ratio $(\mathrm{S} / \mathrm{N})$, and occurrence of confirmation ions (not for MON, all three of BEA) were required for detectable concentrations of each mycotoxin. The lowest detectable peak
Table 4 Ion ratio, limit of detection (LOD), limit of quantification (LOQ), quantitative range, and recovery percentage of the mycotoxins with two different concentration levels

\begin{tabular}{lllllll}
\hline Mycotoxin & Ion ratio $^{\mathrm{a}} \pm \mathrm{SD}^{\mathrm{b}}$ & $\begin{array}{l}\mathrm{LOD}_{\mathrm{ng} \mathrm{g}}{ }^{-1} \\
\text { Moniliformin }\end{array}$ & $\begin{array}{l}\mathrm{LOQ} \\
\mathrm{ng} \mathrm{g}^{-1}\end{array}$ & $\begin{array}{l}\text { Quantitative } \\
\text { range } \mathrm{ng} \mathrm{g}^{-1}\end{array}$ & $\begin{array}{l}\text { Recovery \% } \\
5 \mathrm{ng} \mathrm{g}^{-1} \pm \mathrm{SD}\end{array}$ & $\begin{array}{l}\text { Recovery \% } \\
50 \mathrm{ng} \mathrm{g}^{-1} \pm \mathrm{SD}\end{array}$ \\
\hline Fumonisin $\mathrm{B}_{1}$ & $1.35 \pm 0.12$ & 2.5 & 5.0 & $5.0-500$ & $110.5 \pm 22.1$ & $96.5 \pm 15.0$ \\
Fumonisin $\mathrm{B}_{2}$ & $1.73 \pm 0.16$ & 2.5 & 10.0 & $10.0-500$ & $66.7 \pm 5.6$ & $98.3 \pm 3.7$ \\
Fumonisin $\mathrm{B}_{3}$ & $2.84 \pm 0.35$ & 2.5 & 10.0 & $10.0-500$ & $82.9 \pm 11.5$ & $99.0 \pm 3.1$ \\
Beauvericin & $0.37 \pm 0.03$ & 1.0 & 2.5 & $2.5-500$ & $97.5 \pm 2.7$ & $97.0 \pm 1.9$ \\
\hline
\end{tabular}

${ }^{\mathrm{a}}$ Ion ratio = quantification ion:confirmation ion, for beauvericin only the first ion ratio is shown

${ }^{\mathrm{b}} \mathrm{SD}$, standard deviation 
areas were used for calculating LOD and LOQ: LOD was calculated as average peak area $+3 \times$ standard deviation (SD) and LOQ as average peak area $+6 \times$ SD (MIKES 2005). Other definitions for LOD and LOQ have also been used, e.g., Yogendrarajah et al. (2013) defined LOD and LOQ as the lowest concentrations at which the target analytes produced a peak signal of three and ten times of the background noise, respectively.

MON was quantified with $\mathrm{ESI}^{-}$ionization. Quantification with $\mathrm{ESI}^{-}$quite often contains less interference signals than with $\mathrm{ESI}^{+}$, so the required S/N could be lower for compounds quantified with $\mathrm{ESI}^{-}$ than with $\mathrm{ESI}^{+}$(Sewram et al. 1999). Onion standard $1.0 \mathrm{ng} \mathrm{g}^{-1}(\mathrm{~S} / \mathrm{N} \geq 5.9)$ was used for LOD and LOQ calculation for MON with $\mathrm{ESI}^{-}$ionization. With onion extract, the LOD for MON was $2.5 \mathrm{ng} \mathrm{g}^{-1}$ and LOQ was $5.0 \mathrm{ng} \mathrm{g}^{-1}$ (Table 4). The quantitative range for MON in onion matrix after concentration was from 5 to $500 \mathrm{ng} \mathrm{g}^{-1}$ (Table 4), whereas in the pure UHPLC gradient it was only from 50 to $500 \mathrm{ng} \mathrm{g}^{-1}$.

BEA and FBs were quantified with $\mathrm{ESI}^{+}$ionization. The onion standards $0 \mathrm{ng} \mathrm{g}^{-1}(\mathrm{~S} / \mathrm{N} \geq 15)$ and $1.0 \mathrm{ng} \mathrm{g}^{-1}(\mathrm{~S} / \mathrm{N} \geq 15)$ were the lowest standards included in the calculations of LOD and LOQ for BEA and FBs, respectively. For BEA in the onion extract, the LOD was $1.0 \mathrm{ng} \mathrm{g}^{-1}$ and LOQ $2.5 \mathrm{ng} \mathrm{g}^{-1}$. For FBs, the calculated LOD was $2.5 \mathrm{ng} \mathrm{g}^{-1}$ and LOQ $10 \mathrm{ng}$ $\mathrm{g}^{-1}$ (Table 4). The quantitative range for BEA was from 2.5 to $500 \mathrm{ng} \mathrm{g}^{-1}$ and for FBs from 10 to $500 \mathrm{ng} \mathrm{g}^{-1}$ (Table 4). a)
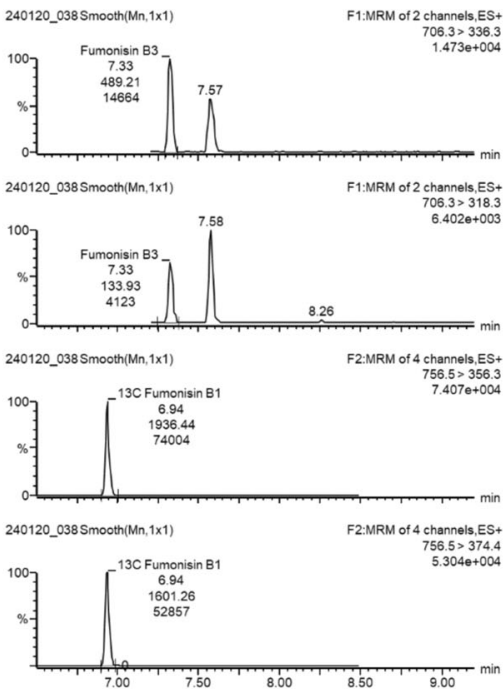

d)

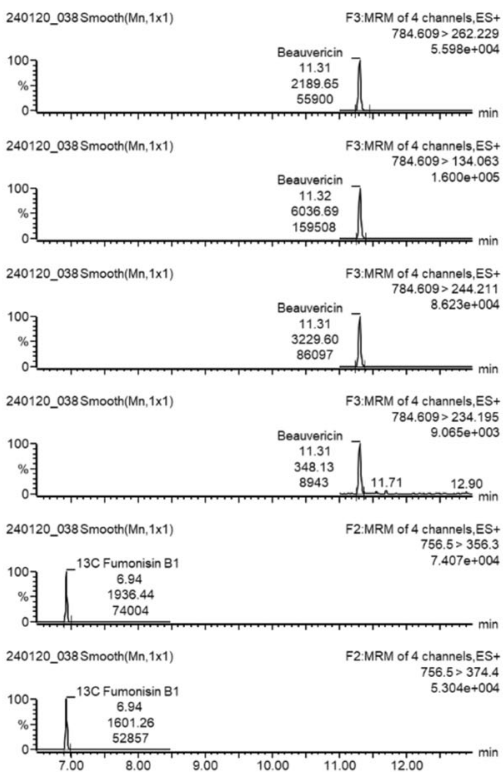

b)
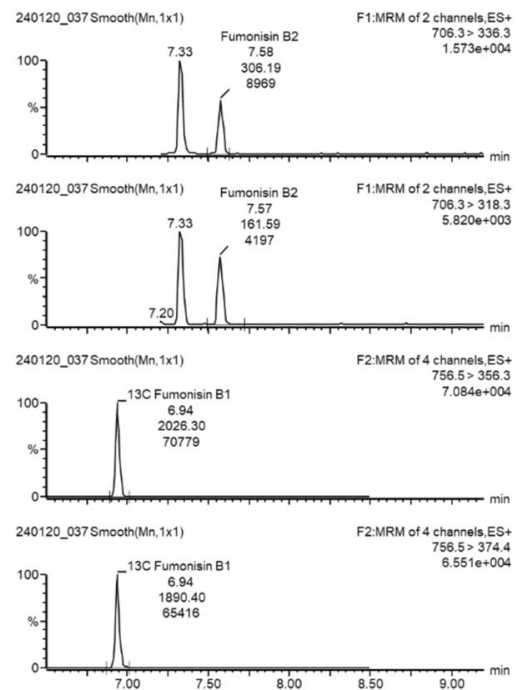

e)

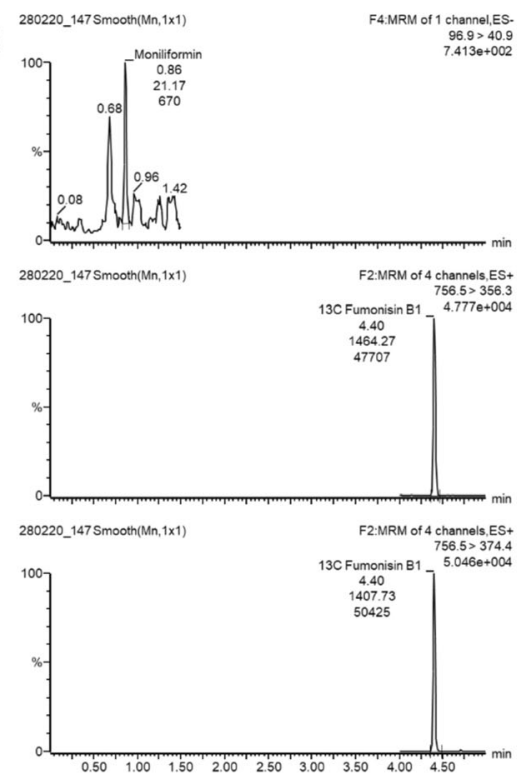

c)
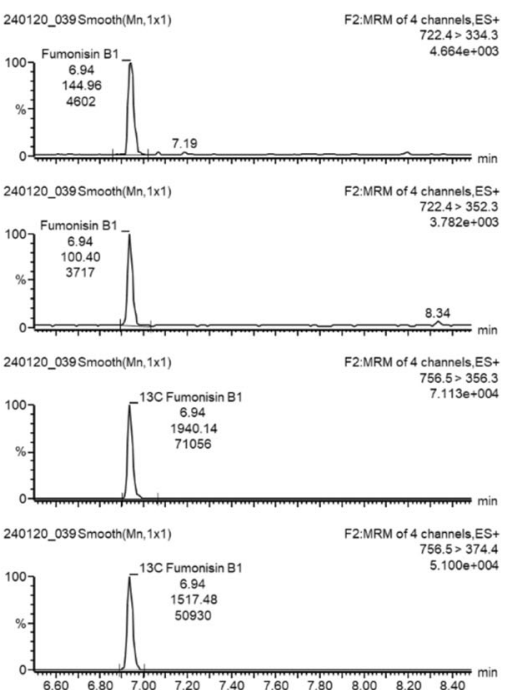

Fig. 1 Multiple reaction monitoring (MRM) chromatograms of the recovery tests with each of the following mycotoxins added at $5.0 \mathrm{ng} \mathrm{g}^{-1}$ concentration in uninfected onion matrix: a fumonisin $\mathrm{B}_{3}$, $\mathbf{b}$ fumonisin
$\mathrm{B}_{2}$, c fumonisin $\mathrm{B}_{1}, \mathbf{d}$ beauvericin, and $\mathbf{e}$ moniliformin. ${ }^{13} \mathrm{C}$-Fumonisin $\mathrm{B}_{1}$ was used as an internal standard 
The recovery tests were performed using two concentrations of toxins, $5.0 \mathrm{ng} \mathrm{g}^{-1}$ and $50 \mathrm{ng} \mathrm{g}^{-1}$, in uninfected onion matrix with three replicates. The recoveries (\%) obtained with these two added concentrations are presented in Table 4 and the MRM chromatograms for $5.0 \mathrm{ng} \mathrm{g}^{-1}$ runs are shown in Fig. 1. Results from the recovery test confirmed the LOQ for MON (5.0 $\mathrm{ng} \mathrm{g}^{-1}$ ), which has no useful confirmation ion (Fig. 1e). The largest quantitative range was achieved for BEA, from 2.5 to $500 \mathrm{ng} \mathrm{g}^{-1}$.

\section{Analysis of Onion Samples}

The method developed in this study was used to analyze 18 samples of onions with FBR symptoms that had been found in the harvest from the farmer's fields in 2017 and from the field trials in 2018. The onions harvested in 2017 had more severe FBR symptoms than the onions in 2018. The symptomatic tissues, showing gray discoloration and softening, and the non-symptomatic tissues were analyzed separately for each onion. The species-specific PCR tests, both the end-point and real-time PCR, showed that all the tested symptomatic onions were infected with $F$. oxysporum. In addition, three of the onions harvested in 2018 were infected with $F$. proliferatum, so these onions had a mixed infection with two Fusarium species associated with FBR. High concentrations of $F$. oxysporum DNA were detected not only in the symptomatic tissues but also in the symptomless tissues of the infected onions (Table 5). Due to the high variation between the samples, the difference in the amount of $F$. oxysporum DNA in the symptomatic and symptomless tissues was only marginally significant $(p=0.0958$, paired $t$-test run with $R$ program). However, for the mycotoxins BEA and MON, the difference between the symptomatic and symptomless tissues was significant (Table 5). In the 2017 samples, quantifiable amounts of BEA were detected in seven out of the eight symptomatic samples, at concentrations between 15 and $411 \mathrm{ng} \mathrm{g}^{-1}$, and one sample contained a trace amount of BEA. Of the symptomless samples, only three contained a trace amount of BEA. Quantifiable amounts of MON were detected in the symptomatic tissues of two onions out of eight, at concentrations of 5 and $82 \mathrm{ng} \mathrm{g}^{-1}$, and four samples contained a trace amount of MON. In the 2018 samples, quantifiable amounts of BEA were detected in all the symptomatic tissue samples, at concentrations between 13 and $752 \mathrm{ng} \mathrm{g}^{-1}$. Quantifiable amounts of MON were detected in seven out of the ten symptomatic samples, at concentrations between 5 and $263 \mathrm{ng} \mathrm{g}^{-1}$, and two samples contained a trace amount of MON. Of the symptomless samples, six contained MON at concentrations between 7 and $49 \mathrm{ng} \mathrm{g}^{-1}$, and two had trace amounts.

Comparison between the samples of symptomatic tissues from the different years 2017 and 2018 showed that the average amounts of BEA were approximately at the same level, despite the vast difference in the average amount of $F$. oxysporum DNA detected. Spearman's correlation test including all the symptomatic tissue samples showed no significant correlation between the amount of $F$. oxysporum DNA and the amount of BEA, whereas a significant correlation was found among the samples from 2017, at the significance level 0.05 ( $r_{s}=0.6667, N=8$, correlation test run with $R$ program). The amounts of MON were higher in 2018 than in 2017, despite the smaller amounts of $F$. oxysporum. Especially, in the symptomless tissues the average amount of MON was significantly higher in 2018 than in 2017 ( $p=0.0185$, two sample $t$ test run with $R$ program). The amount of MON in the symptomatic tissues showed a significant negative correlation with

Table 5 Summary of the results of Fusarium oxysporum detection and mycotoxin detection in symptomatic onions

\begin{tabular}{|c|c|c|c|c|c|c|c|}
\hline \multirow[t]{2}{*}{ Sample set } & \multirow[t]{2}{*}{ Onion tissue } & \multicolumn{2}{|c|}{ Fox:onion DNA ratio pg $\mu \mathrm{g}^{-1}$} & \multicolumn{2}{|c|}{ Beauvericin $\mathrm{ng} \mathrm{g}^{-1}$} & \multicolumn{2}{|c|}{ Moniliformin $\mathrm{ng} \mathrm{g}^{-1}$} \\
\hline & & Median & Mean $\pm \mathrm{SD}^{\mathrm{a}}$ & Median & Mean $\pm \mathrm{SD}$ & Median & Mean $\pm \mathrm{SD}$ \\
\hline \multirow[t]{3}{*}{ All $(N=18)$} & Symptomatic & 24,980 & $1,166,072 \pm 3,634,068$ & 144.0 & $197.8 \pm 202.6$ & 3.75 & $41.64 \pm 83.27$ \\
\hline & Symptomless & 85 & $3250 \pm 7042$ & 1.00 & $1.31 \pm 1.66$ & 1.25 & $7.36 \pm 13.59$ \\
\hline & Difference $^{\mathrm{b}}$ & & Not significant $(p>0.05)$ & & Significant $(p<0.001)$ & & Significant $(p=0.0298)$ \\
\hline \multirow[t]{3}{*}{$2017(N=8)$} & Symptomatic & 553,333 & $2,587,125 \pm 5,283,246$ & 128.0 & $179.8 \pm 178.9$ & 2.50 & $11.81 \pm 28.41$ \\
\hline & Symptomless & 636 & $5004 \pm 9493$ & 0 & $0.38 \pm 0.52$ & 0 & $0.31 \pm 0.88$ \\
\hline & Difference & & Not significant $(p>0.05)$ & & Significant $(p=0.0125)$ & & Not significant $(p>0.05)$ \\
\hline \multirow[t]{3}{*}{$2018(N=10)$} & Symptomatic & 3884 & $29,230 \pm 67,942$ & 144.0 & $212.2 \pm 228.2$ & 6.50 & $65.50 \pm 105.09$ \\
\hline & Symptomless & 85 & $1846 \pm 4318$ & 1.00 & $2.05 \pm 1.89$ & 7.00 & $13.00 \pm 16.40$ \\
\hline & Difference & & Not significant $(p>0.05)$ & & Significant $(p=0.0087)$ & & Not significant $(p>0.05)$ \\
\hline
\end{tabular}

${ }^{\text {a }} S D$, standard deviation

${ }^{\mathrm{b}}$ The difference in means between the symptomatic and symptomless tissues of the onions was analyzed by paired $t$-test in $R$, at confidence level 0.95 . In the statistical analyses, LOD values $\left(2.5 \mathrm{ng} \mathrm{g}^{-1}\right.$ for moniliformin and $1.0 \mathrm{ng} \mathrm{g}^{-1}$ for beauvericin) were used for the trace (under LOQ) amounts of the mycotoxins 
the amount of $F$. oxysporum DNA (Spearman's correlation, $r_{s}$ $=-0.4985, N=18$ ), due to the smaller amount of fungus and higher amount of MON in the 2018 samples. However, when viewing the samples from different years separately, the correlations between the amount of the fungus and MON were not significant. Because of the small number of samples in this study, which was performed in order to test the new toxin analysis method, these results are preliminary. It is possible, however, that the amount of toxin production in $F$. oxysporum varies between the different strains of the fungus and/or is dependent on the environmental factors, and thus does not directly reflect the amount of the fungus.

Three onions were found to contain $F$. proliferatum DNA at

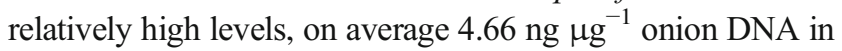
the symptomatic tissue. In two of these symptomatic samples, $\mathrm{FB}_{1}$ was detected, at concentrations 32 and $33 \mathrm{ng} \mathrm{g}^{-1}$, and trace amounts of $\mathrm{FB}_{2}$ and $\mathrm{FB}_{3}$ were found in the same samples. Only trace amounts of FBs were detected in the symptomless tissues of the same onions, and the symptomless tissues also contained less $F$. proliferatum DNA. No FBs were detected in the samples that did not contain $F$. proliferatum, suggesting that the FBs detected were produced by $F$. proliferatum and that $F$. oxysporum did not produce these toxins in onion. These results agree with the previous study by Waskiewicz and Stepien (2012) showing that plant-derived $F$. proliferatum isolates produced FBs in vitro, whereas these toxins were not produced by $F$. oxysporum.

\section{Conclusions}

In this study, a new method based on MRM UHPLC-MS/MS technique was developed and validated for onion matrix for detection of multiple mycotoxins produced by Fusarium species. Fumonisins $\mathrm{B}_{1}, \mathrm{~B}_{2}$, and $\mathrm{B}_{3}\left(\mathrm{FB}_{1}, \mathrm{FB}_{2}\right.$ and $\left.\mathrm{FB}_{3}\right)$, beauvericin (BEA), and moniliformin (MON), the main mycotoxins produced by $F$. oxysporum and $F$. proliferatum, were detected and quantified. Samples were prepared from the fined onion tissues using methanol:water (3:1) extraction with magnetic stirring, and no cleanup was needed prior to analysis. FBs and BEA could be determined directly from the filtered sample extracts, whereas detection of MON required sample concentration. Internal standard ${ }^{13} \mathrm{C}-\mathrm{FB}_{1}$ was used to identify and quantify the target mycotoxins, and the limit of quantification was from 2.5 to $10 \mathrm{ng} \mathrm{g}^{-1}$ in onion matrix. The method was successfully employed for the analysis of mycotoxins in harvested onions that were naturally infected with $F$. oxysporum and $F$. proliferatum and showed FBR symptoms. In the onions infected with $F$. oxysporum but not with $F$. proliferatum, only MON and BEA were detected. In the onions with mixed infection with both $F$. oxysporum and $F$. proliferatum, fumonisins were detected in addition to $\mathrm{MON}$ and BEA. The quantifiable amounts of toxins were mostly found in the symptomatic tissues of the infected onions. However, MON was also detected in some of the symptomless tissues, which raises the question of food safety in case of those Fusarium-infected onions that do not yet display disease symptoms.

Acknowledgements We are greatly thankful to our colleague Asko Hannukkala, who recently passed away, for his contribution to this work. We thank Leena Holkeri, Senja Tuominen, Aila Siren, Marjaana Virtanen, and Riitta Henriksson at the Natural Resources Institute Finland (Luke) for technical assistance.

Availability of Data and Materials Not applicable.

Code Availability Not applicable.

Author Contribution All authors contributed to the study conception and design. Disease diagnostics, material preparation, and end-point PCR were performed by Satu Latvala, real-time PCR analysis by Minna Haapalainen, and mycotoxin UHPLC-MS/MS analysis and method validation by Sari Rämö. The first draft of the manuscript was written by Sari Rämö and Satu Latvala and all authors commented on previous versions of the manuscript. All authors read and approved the final manuscript.

Funding Open access funding provided by Natural Resources Institute Finland (LUKE). This work was supported by Maiju ja Yrjö Rikalan Puutarhasäätiö.

\section{Declarations}

Ethics Approval This article does not contain any studies with human participants or animals performed by any of the authors.

Consent to Participate Not applicable.

Consent for Publication Not applicable.

Conflict of Interest Sari Rämö declares that she has no conflict of interest. Minna Haapalainen declares that she has no conflict of interest. Satu Latvala declares that she has no conflict of interest.

Open Access This article is licensed under a Creative Commons Attribution 4.0 International License, which permits use, sharing, adaptation, distribution and reproduction in any medium or format, as long as you give appropriate credit to the original author(s) and the source, provide a link to the Creative Commons licence, and indicate if changes were made. The images or other third party material in this article are included in the article's Creative Commons licence, unless indicated otherwise in a credit line to the material. If material is not included in the article's Creative Commons licence and your intended use is not permitted by statutory regulation or exceeds the permitted use, you will need to obtain permission directly from the copyright holder. To view a copy of this licence, visit http://creativecommons.org/licenses/by/4.0/.

\section{References}

Al-Taher F, Cappozzo J, Zweigenbaum J, Lee HJ, Jackson L, Ryu D (2017) Detection and quantitation of mycotoxins in infant cereals 
in the U.S. market by LC-MS/MS using a stable isotope dilution assay. Food Control 72:27-35. https://doi.org/10.1016/j.foodcont. 2016.07.027

Bayraktar H, Dolar FS (2011) Molecular identification and genetic diversity of Fusarium species associated with onion fields in Turkey. J Phytopathol 159:28-34. https://doi.org/10.1111/j.1439-0434.2010. 01715.x

Carrieri R, Raimo F, Pentangelo A, Lahoz E (2013) Fusarium proliferatum and Fusarium tricinctum as causal agents of pink rot of onion bulbs and the effect of soil solarization combined with compost amendment in controlling their infections in field. Crop Protection 43:31-37. https://doi.org/10.1016/j.cropro.2012.09.013

Desjardins AE, Proctor RH (2007) Molecular biology of Fusarium mycotoxins. Int J Food Microbiol 119(1-2):47-50. https://doi.org/10. 1016/j.jifoodmicro.2007.07.024

Dong H, Xian Y, Xiao K, Wu Y, Zhu L, He J (2019) Development and comparison of single-step solid phase extraction and QuEChERS clean-up for the analysis of 7 mycotoxins in fruits and vegetables during storage by UHPLC-MS/MS. Food Chem. 274:471-479. https://doi.org/10.1016/j.foodchem.2018.09.035

EC (2006) Commission regulation (EC) no $1881 / 2006$ of 19 December 2006 setting maximum levels for certain contaminants in foodstuffs

Ellner F, Grossmann M (2010) Pathogenicity and toxin production of Fusarium oxysporum and Fusarium proliferatum in onion bulbs. Julius-Kühn-Archiv No 428:192

European Committee for Standardization (CEN) (2004) Foodstuffs - determination of fumonisin B1 and B2 in maize based foods - HPLC method with immunoaffinity column clean up EN 14352:2005

Fremy J-M, Alassane-Kpembi I, Oswald IP, Cottrill B, Van Egmond HP (2019) A review on combined effects of moniliformin and cooccurring Fusarium toxins in farm animals. World Mycotoxin Journal 12(3):281-291. https://doi.org/10.3920/WMJ2018.2405

Galvan GA, Koning-Boucoiran CFS, Koopman WJM, Burger-Meijer K, Gonzalez PH, Waalwijk C, Kik C, Scholten OE (2008) Genetic variation among Fusarium isolates from onion, and resistance to Fusarium basal rot in related Allium species. Eur J Plant Pathol 121:499-512. https://doi.org/10.1007/s10658-008-9270-9

Haapalainen M, Latvala S, Kuivainen E, Qiu Y, Segerstedt M, Hannukkala AO (2016) Fusarium oxysporum, F. proliferatum and $F$. redolens associated with basal rot of onion in Finland. Plant Pathol 65:1310-1320. https://doi.org/10.1111/ppa.12521

Hietaniemi V, Kontturi M, Rämö S, Eurola M, Kangas A, Niskanen M, Saastamoinen M (2004) Contents of trichothecenes in oats during official variety, organic cultivation and nitrogen fertilization trials in Finland. Agric Food Sci 13:54-67

Hietaniemi V, Rämö S, Yli-Mattila T, Jestoi M, Peltonen S, Kartio M, Sieviläinen E, Koivisto K, Parikka P (2016) Updated survey of Fusarium species and toxins in Finnish cereal grains. Food Additives \& Contaminants: Part A 33. NO. 5:831-848. https://doi. org/10.1080/19440049.2016.1162112

Irzykowska L, Bocianowski J, Waskiewicz A, Weber Z, Karolewski Z, Golinski P, Kostecki M, Irzykowski W (2012) Geneteic variation of Fusarium oxysporum isolates forming fumonisin B1 and moniliformin. J Appl Genet 53:237-247. https://doi.org/10.1007/ s13353-012-0087-z

Jajić I, Dudaš T, Krstović S, Krska R, Sulyok M, Bagi F, Savić Z, Guljaš D, Stankov A (2019) Emerging Fusarium mycotoxins fusaproliferin, beauvericin, enniatins, and moniliformin in Serbian maize. Toxins 11:357. https://doi.org/10.3390/toxins 11060357

Jestoi M (2008) Emerging fusarium-mycotoxins fusaproliferin, beauvericin, enniatins, and moniliformin - a review. Crit Rev Food Sci Nutr 48(1):21-49. https://doi.org/10.1080/ 10408390601062021

Jestoi M, Rokka M, Rizzo A, Peltonen K, Parikka P, Yli-Mattila T (2003) Moniliformin in Finnish grains: Analysis with LC-MS/MS. Asp Appl Biol 68:211-216
Kangethe EK, Sirma AJ, Murithi G, Mburugu-Mosoti CK, Ouko EO, Korhonen HJ, Nduhiu GJ, Mungatu JK, Joutsjoki V, Lindfors E, Ramo S (2017) Occurrence of mycotoxins in food, feed, and milk in two counties from different agroecological zones and with historical outbreak of aflatoxins and fumonisins poisonings in Kenya. Food Quality and Safety 1(3):161-169. https://doi.org/10.1093/fqsafe/ fyx018

Kokkonen MK, Jestoi MN (2009) A multi-compound LC-MS/MS method for the screening of mycotoxins in grains. Food Anal Methods 2: 128-140. https://doi.org/10.1007/s12161-008-9051-2

Lee HJ, Ryu D (2015) Advances in mycotoxin research: public health perspectives. J Food Sci 80(12):2970-2983. https://doi.org/10.1111/ 1750-3841.13156

Mahnine N, Meca G, Fernández-Franzón M, Mañes J, Zinedine A (2012) Occurrence of fumonisins B1, B2, B3 in breakfast and infant cereals from Morocco. Phytopathol Mediterr 51(1):193-197. https://doi. org/10.14601/Phytopathol_Mediterr-9472

Malysheva SV, Di Mavungu JD, Goryacheva IY, De Saeger S (2013) A systematic assessment of the variability of matrix effects in LC-MS/ MS analysis of ergot alkaloids in cereals and evaluation of method robustness. Anal Bioanal Chem 405:5595-5604. https://doi.org/10. 1007/s00216-013-6948-4

Marin S, Ramos AJ, Gano-Sancho G, Sanchos V (2013) Review mycotoxins: Occurrence, toxicology, and exposure assessment. Food Chem Toxicol 60:218-237. https://doi.org/10.1016/j.fct.2013.07. 047

MIKES Metrologia (2005) Kemian metrologian opas J6/2005. Edited by Tapio Ehder, Metrologian neuvottelukunta, Kemian ja mikrobiologian jaosto, Kemian työryhmä. Helsinki. https://www. vttresearch.com/sites/default/files/pdf/MIKES/2005-J6.pdf

Molinelli A, Grossalber K, Krska R (2009) A rapid lateral flow test for the determination of total type $\mathrm{B}$ fumonisins in maize. Anal Bioanal Chem 395:1309-1316. https://doi.org/10.1007/s00216-009-3082-4

Monbaliu S, Van Poucke C, Van Peteghem C, Van Poucke K, Heungens K, De Saeger S (2009) Development of a multi-mycotoxin liquid chromatography/tandem mass spectrometry method for sweet pepper analysis. Rapid Commun Mass Spectrom 23(1):3-11. https:// doi.org/10.1002/rcm.3833

Parich A, Schuch Boeira L, Perez Castro S, Krska R (2003) Determination of moniliformin using SAX column clean-up and HPLC/DAD-detection. Mycotoxin Res 19:203-206

Rubert J, Soler C, Mañes J (2011) Evaluation of matrix solid-phase dispersion (MSPD) extraction for multi-mycotoxin determination in different flours using LC-MS/MS. Talanta 85:206-215. https:// doi.org/10.1016/j.talanta.2011.03.046

Rubert J, Soler C, Mañes J (2012) Application of an HPLC-MS/MS method for mycotoxin analysis in commercial baby foods. Food Chem 133:176-183. https://doi.org/10.1016/j.foodchem.2011.12. 035

Sadhasivam S, Britzi M, Zakin V, Kostyukovsky M, Trostanetsky A, Quinn E, Sionov E (2017) Rapid detection and identification of mycotoxigenic fungi and mycotoxins in stored wheat grain. Toxins 9:302. https://doi.org/10.3390/toxins9100302

SANTE/12089/2016, Guidance document on identification of mycotoxins in food and feed

Sasaki K, Nakahara K, Tanaka S, Shigyo M, Ito S (2015a) Genetic and pathogenic variability of Fusarium oxysporum f. sp. isolated from onion and Welsh onion in Japan. Phytopathology 105:525-532. https://doi.org/10.1094/PHYTO-06-14-0164-R

Sasaki K, Nakahara K, Shigyo M, Tanaka S, Ito S (2015b) Detection and quantification of onion isolates of Fusarium oxysporum $\mathrm{f}$. sp. cepae in onion plant. J Gen Plant Pathol 81:232-236. https://doi.org/10. 1007/s10327-015-0589-8

Serrano AB, Font G, Mañes J, Ferrer E (2013) Comparative assessment of three extraction procedures for determination of emerging 
Fusarium mycotoxins in pasta by LC-MS/MS. Food Control 32: 105-114. https://doi.org/10.1016/j.foodcont.2012.11.037

Sewram V, NieuWoudt TW, Marasas WFO, Shephard GS, Ritieni A (1999) Determination of the mycotoxin moniliformin in cultures of Fusarium subglutinans and in naturally contaminated maize by high-performance liquid chromatography-atmospheric pressure chemical ionization mass spectrometry. J Chromatogr A 848:185191

Shephard GS, Marasas WFO, Burger H-M, Somdyala NIM, Rheeder JP, Van der Westhuizen L, Gatyeni P, Van Schalkwyk DJ (2007) Exposure assessment for fumonisins in the former Transkei region of South Africa. Food Addit Contam 24(6):621-629. https://doi.org/ 10.1080/02652030601101136

Stankovic S, Levic J, Petrovic T, Logrieco A, Moretti A (2007) Pathogenicity and mycotoxin production by Fusarium proliferatum isolated from onion and garlic in Serbia. Eur J Plant Pathol 118:165172. https://doi.org/10.1007/s10658-007-9126-8

Stead S, Roberts D, Gledhill A, de Rijk T, Van Poucke C, De Saeger S (2014) The development of a sensitive multi-residue LC-MS/MS method for the quantitative determination of mycotoxins in animal feedstuffs and silage using Xevo TQ-S. https://www.waters.com/ webassets/cms/library/docs/720004961en.pdf

Taylor A, Vagany V, Barbara DJ, Thomas B, Pink DAC, Jones JE, Clarkson JP (2013) Identification of differential resistance to six Fusarium oxysporum f. sp. cepae isolates in commercial onion cultivars through the development of a rapid seedling assay. Plant Pathol 62:103-111. https://doi.org/10.1111/j.1365-3059.2012. 02624.x

Turner NW, Bramhmbhatt H, Szabo Vezse M, Poma A, Coker R, Piletsky SA et al (2015) Analytical methods for determination of mycotoxins: an update (2009-2014). Anal Chim Acta 901:12-33. https://doi.org/10.1016/j.aca.2015.10.013
Van de Perre E, Deschuyffeleer N, Jacxsens L, Vekeman F, Van Der Hauwaert W, Asam S, Rychlik M, Devliegher F, De Meulenaer B (2014) Screening of moulds and mycotoxins in tomatoes, bell peppers, onions, soft red fruits and derived tomato products. Food Control 37:165-170. https://doi.org/10.1016/j.foodcont.2013.09. 034

Wang A, Islam MN, Johansen A, Haapalainen M, Latvala S, Edelenbos M (2019) Pathogenic Fusarium oxysporum f. sp. cepae growing inside onion bulbs emits volatile organic compounds that correlate with the extent of infection. Postharvest Biol Technol 152:19-28. https://doi.org/10.1016/j.postharvbio.2019.02.010

Waskiewicz A, Stepien L (2012) Mycotoxins biosynthesized by plantderived Fusarium isolates. Arh Hig Rada Toksikol 63:437-446. https://doi.org/10.2478/10004-1254-63-2012-2230

Waskiewicz A, Golinski P, Karolewski Z, Irzykowska L, Bocianowski J, Kostecki M, Weber Z (2010) Formation of fumonisins and other secondary metabolites by Fusarium oxysporum and F. proliferatum: a comparative study. Food Addit Contam: Part A 27(5):608-615. https://doi.org/10.1080/19440040903551947

Yogendrarajah P, Van Poucke C, De Meulenaer B, De Saeger S (2013) Development and validation of a QuEChERS based liquid chromatography tandem mass spectrometry method for the determination of multiple mycotoxins in spices. J Chromatogr A 1297:1-11. https:// doi.org/10.1016/j.chroma.2013.04.075

Zhao Z, Yang X, Zhao X, Chen L, Bai B, Zhou C, Wang J (2018) Method development and validation for the analysis of emerging and traditional Fusarium mycotoxins in pepper, potato, tomato, and cucumber by UPLC-MS/MS. Food Anal Methods 11:1780-1788. https:// doi.org/10.1007/s12161-018-1180-7

Publisher's Note Springer Nature remains neutral with regard to jurisdictional claims in published maps and institutional affiliations. 